OPEN ACCESS

Edited by:

Hajo Dieringa,

Helmholtz Centre for Materials and Coastal Research (HZG), Germany

Reviewed by:

Sung Bo Lee,

Seoul National University, South Korea

Claudio Pistidda,

Institute of Materials Research, Helmholtz Centre for Materials and Coastal Research (HZG), Germany

*Correspondence:

Yuri Estrin

yuri.estrin@monash.edu

Specialty section:

This article was submitted to

Structural Materials,

a section of the journal

Frontiers in Materials

Received: 25 June 2019

Accepted: 17 September 2019

Published: 04 October 2019

Citation:

Rabkin E, Skripnyuk V and Estrin Y (2019) Ultrafine-Grained Magnesium Alloys for Hydrogen Storage Obtained

by Severe Plastic Deformation.

Front. Mater. 6:240

doi: $10.3389 /$ fmats.2019.00240

\section{Ultrafine-Grained Magnesium Alloys for Hydrogen Storage Obtained by Severe Plastic Deformation}

\author{
Eugen Rabkin ${ }^{1}$, Vladimir Skripnyuk ${ }^{1}$ and Yuri Estrin ${ }^{2,3 *}$
}

${ }^{1}$ Department of Materials Science and Engineering, Technion - Israel Institute of Technology, Haifa, Israel, ${ }^{2}$ Department of Materials Science and Engineering, Monash University, Clayton, VIC, Australia, ${ }^{3}$ Department of Mechanical Engineering, The University of Western Australia, Crawley, WA, Australia

Magnesium alloys take a special place among the hydrogen storage materials, mainly due to their high gravimetric (7.6 mass \%) and volumetric $\left(110 \mathrm{~kg} \mathrm{~m}^{-3}\right)$ hydrogen storage capacity. Unfortunately, the kinetics of hydrogenation and hydrogen release are rather slow, which limits practical use of magnesium-based materials for hydrogen and heat storage. Refining the microstructure of magnesium alloys, ideally down to nanoscale, is known to accelerate the hydrogenation/dehydrogenation kinetics. A possible way to achieve that is by severe plastic deformation. Our first demonstration of this effect through processing of a Mg alloy (ZK60) by equal-channel angular pressing prompted a stream of further studies employing severe plastic deformation techniques to improve the hydrogen storage-relevant properties of Mg alloys. The present article provides an overview of the literature on the subject, with a natural focus on our own data.

Keywords: hydrogen storage, hydrogenation kinetics, magnesium alloys, magnesium-based composites, severe plastic deformation

\section{INTRODUCTION}

Hydrogen storage is a key element of hydrogen economy, and a lot of effort goes into developing viable solutions to this critical need. A particularly attractive answer to the challenging quest is solid-state storage, whereby hydrogen is embedded in the bulk of a host solid (Schlapbach and Züttel, 2001; Jena, 2011; Walker, 2011; Graetz, 2012). Magnesium could be regarded as a perfect host for hydrogen due to its high gravimetric $\left(7.6\right.$ mass \%) and volumetric $\left(110 \mathrm{~kg} \mathrm{~m}^{-3}\right)$ hydrogen storage capacity (Shao et al., 2018), abundance in sea water and the Earth's crust, and low cost (US\$2-3 per kilogram). Furthermore, hydrides it forms with hydrogen $\left(\mathrm{MgH}_{2}\right)$ are highly efficient in terms of the stored energy density $(2.6 \mathrm{kWh} / \mathrm{kg}$-about twice the energy density of liquid hydrogen) (Luo et al., 2019). Problem is that the targeted equilibrium hydrogen pressure of 1 atm $(0.1 \mathrm{MPa})$ cannot be achieved at temperatures that would be acceptable for mobile (notably automotive) hydrogen storage applications. The problem is rooted in a high enthalpy of magnesium hydride formation (Huot, 2010) and is further exacerbated by a sluggish kinetics of absorption and desorption of hydrogen in magnesium-based materials (Schlapbach and Züttel, 2001; Huot, 2010; Jena, 2011; Walker, 2011; Shao et al., 2018; Luo et al., 2019; Yartys et al., 2019). In one of his last publications (Birnbaum, 2005), the nestor of research on hydrogen in metals, Prof. Howard Birnbaum, gave a rather pessimistic outlook on the prospects of overcoming the thermodynamics handicap of magnesium hydrides. He wrote: "While it is always dangerous to predict the course of science, I am not particularly optimistic about our ability to develop a hydride having the desirable properties." Despite his concerns, researchers have been exploring various pathways to 
outsmart the disadvantageous thermodynamics and kinetics of hydride-forming magnesium alloys, and nanostructuring appears to be one of the promising avenues to achieving that, cf. (Hardian et al., 2018; Schneemann et al., 2018; Yartys et al., 2019; Zhang et al., 2019). A popular technique for grain refinement down to nano scale is high energy ball milling (HEBM) of $\mathrm{Mg}$ powders which, indeed, was shown to accelerate the hydrogenation/dehydrogenation kinetics in several Mg alloyswith or without catalysts (Luo et al., 2019). Unfortunately, the cost of production of $\mathrm{Mg}$ alloys with sufficiently good hydrogen sorption properties by HEBM in terms of the processing time, energy input, and labor involved is prohibitively high, which limits the application of this technology at industry scale.

In 2004, we proposed an alternative route to mechanicallydriven nanostructuring of hydride forming Mg alloys (Skripnyuk et al., 2004). It was a first ever attempt to employ severe plastic deformation of bulk metallic specimens to improve their hydrogen absorption/desorption properties. The term severe plastic deformation (SPD) refers to a group of techniques in which a gigantic shear deformation, combined with high hydrostatic pressure, gives rise to extreme grain refinementdown to a deep submicron scale and in some cases to nano scale [see e.g. (Valiev et al., 1999, 2016; Estrin and Vinogradov, 2013)]. Combined with a high density of crystal lattice defects generated, SPD-induced grain refinement was seen as a potent mechanism of accelerated hydrogen sorption of $\mathrm{Mg}$ alloys. The encouraging results of that study in terms of faster reversible hydrogenation/dehydrogenation prompted other researchers to pursue this processing route, and a significant number of publications reporting their results ensued. While these studies still constitute a niche research area, the interest in the potential of SPD as a means of combating the unfavorable thermodynamics and kinetics of hydrogenation of $\mathrm{Mg}$ alloys is great, and we feel that a "mini-review" of this area would be conducive for promoting it to a broader research community. In what follows, such an overview is provided.

\section{ACCELERATED HYDROGEN SORPTION KINETICS IN MAGNESIUM ALLOYS ACHIEVED BY SEVERE PLASTIC DEFORMATION}

\section{Alloys Processed by Equal-Channel Angular Pressing}

We begin by summarizing the results of the mentioned study (Skripnyuk et al., 2004), as they are representative of the research in this field heralded in that publications. The material investigated was $\mathrm{Mg}-4.95 \mathrm{wt} \% \mathrm{Zn}-0.71 \mathrm{wt} \% \mathrm{Zr}$ (ZK60)a common commercial magnesium alloy broadly used for structural applications. The SPD technique employed was equal channel angular pressing (ECAP), in which a billet is pressed through an angular die and experiences a large shear strain when it passes through a plane at which the entry and the exit channels meet. For a $90^{\circ}$ die, this shear strain is of the order of $100 \%$. As in this process the cross-sectional dimensions of the billet remain unchanged, pressing can be repeated several times, so that the cumulative strain can reach levels not achievable in conventional metal forming. The outcomes of processing of many alloys in terms of microstructure variation are astounding: the grain size drops typically well below $1 \mu \mathrm{m}$, and in many cases reaches a $100 \mathrm{~nm}$ range (Valiev et al., 1999, 2016; Estrin and Vinogradov, 2013), and Mg alloys are no exception (see e.g., Orlov et al., 2011).

To compare the effect of various processing routes on the microstructure and the ensuing thermodynamic and kinetic properties of alloy ZK60, it was modified by HEBM, ECAP, or a combination of both methods. To that end, pressurecomposition-temperature (PCT) diagrams and the kinetics of hydrogen desorption in a closed volume system were determined for the alloy in the initial (annealed) condition and upon mechanically-driven nanostructuring. A special ECAP schedule used involved eight passes through a $120^{\circ}$ angular die at elevated temperatures $\left(250\right.$ or $\left.300^{\circ} \mathrm{C}\right)$ followed by a final pass through a $90^{\circ}$ die at room temperature. Route A (in which the billet is not rotated between the passes) was used. Microstructure characterization by transmission electron microscopy revealed a drop in the average grain size from $46 \mu \mathrm{m}$ in the initial condition to $0.5-2 \mu \mathrm{m}$ in the ECAP-processed one. HEBM processing was carried out using a standard procedure described in Skripnyuk et al. (2004). Before hydrogenation tests, annealed and mechanically processed specimens were comminuted by filing with a rasp. The particles produced in this way, $<1 \mathrm{~mm}$ in size, were hydrogenated at $300^{\circ} \mathrm{C}$ and hydrogen pressure of 25 atm, and then underwent desorption-absorption cycles.

Representative PCT diagrams for alloy ZK60 processed by ECAP and HEBM are shown in Figure 1 vis-à-vis the PCT diagram for the annealed reference alloy (Skripnyuk et al., 2004). As seen from Figure 1, both straight ECAP and combined ECAP/HEBM processing affect the PCT diagrams. Both raise the equilibrium hydrogen pressure at the left flank of the pressure plateau and tilt the entire plateau region of the PCT diagram toward a horizontal direction. A further important observation was the disappearance of pressure hysteresis for the ECAP/HEBM processed material.

The beneficial effect of ECAP on the hydrogenation properties was enhanced when the ECAP processing temperature was raised from 250 to $300^{\circ} \mathrm{C}$, causing a doubling of the hydrogen desorption pressure in the plateau region of the PC isotherm. A substantial increase of the hydrogen desorption rate was also found, especially in the low temperature range. The difference in hydrogenation behavior can be correlated with the degree of uniformity and the morphology of dehydrogenated powders. Indeed, the powders produced from the samples deformed at $300^{\circ} \mathrm{C}$ were more homogeneous and finely dispersed, and their morphology was less faceted than those obtained from the samples deformed at $250^{\circ} \mathrm{C}$ (Skripnyuk et al., 2009).

The effects observed can be associated with the ECAP-induced changes in the microstructure and the defect structure of the alloy. It is believed that a fairly uniform microstructure with a low number of twin boundaries and a large volume fraction of small grains was conducive for better hydrogenation kinetics. The chemistry, morphology and distribution of finely dispersed zinczirconium precipitates in the ECAP-processed alloy are further 

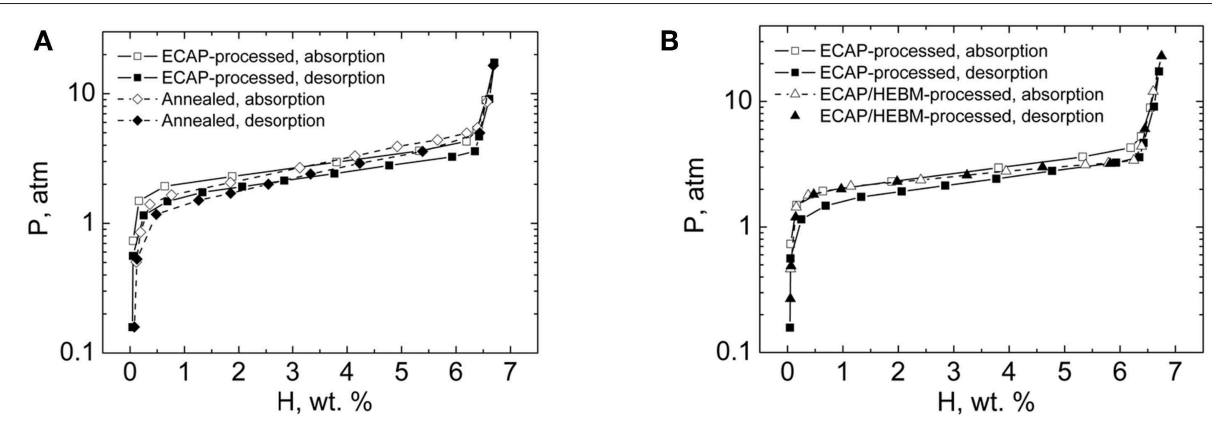

FIGURE 1 | PCT diagrams for annealed and mechanically processed alloy ZK60: (A) ECAP-treated vs. annealed condition; (B) ECAP vs. combined ECAP/HEBM conditions. The hydrogen absorption/desorption measurements were conducted in a Sievert's apparatus at $300^{\circ} \mathrm{C}$. Reproduced from Skripnyuk et al. (2004) with permission from Elsevier.

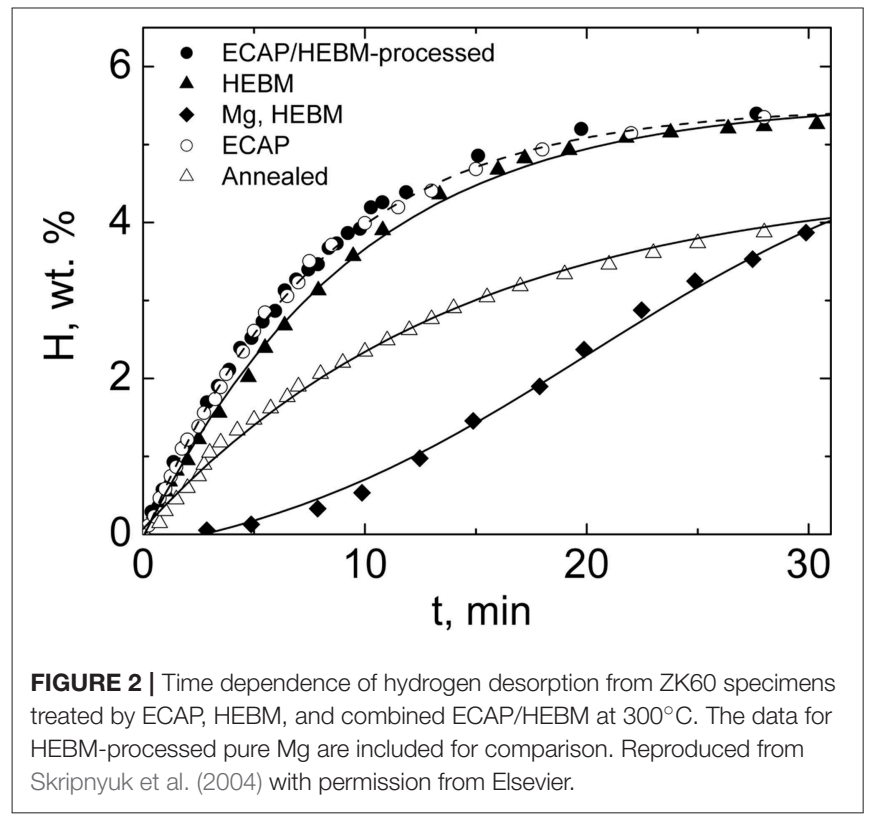

factors specific for alloy ZK60, which may have contributed to the increase of hydrogen desorption pressure.

A result of the study (Skripnyuk et al., 2004) most significant for practical hydrogen storage applications was a marked acceleration of the hydrogen desorption kinetics due to ECAP or ECAP+HEBM treatment, which is seen in Figure 2. The effect of ECAP conducted according to the schedule outlined above was on par with that of $15 \mathrm{~h}$ of HEBM. The benefits of grain refinement by any of these processing techniques in terms of the enhancement of the desorption rate are obvious. ECAP has a definite advantage over HEBM as it allows processing of bulk billets within a shorter time than HEBM. In addition to higher productivity, ECAP has an advantage of being a much safer process, as it does not require handling of potentially hazardous powder materials. More detailed data on hydrogen storage properties of ECAP-processed alloy ZK60, including the temperature dependence of the sorption kinetics were provided in Skripnyuk et al. (2009).
Encouraged by these results, other researchers have followed suit and adopted ECAP as a means to improve the hydrogenation/dehydrogenation kinetics of $\mathrm{Mg}$ alloys. Thus, Krystian et al. (2011) used a different schedule of ECAP processing of alloy ZK60 and were able to reduce the average grain size to $250 \mathrm{~nm}$ and achieve a higher hydrogen uptake and further acceleration of the desorption kinetics, cf. Figure 2 in Krystian et al. (2011). Comparison of these results with the effect of other mechanical processing routes on the hydrogenation/dehydrogenation behavior of alloy ZK60, such as cold rolling (Wang et al., 2010), shows that ECAP outperforms the latter.

Other authors (Soyama et al., 2016) using ECAP for the same purpose, yet for an alloy with a somewhat different composition (ZK60 with added 2.5\% Mischmetal) were not able to achieve similar levels of improvement of hydrogen sorption kinetics by ECAP treatment, however. An important observation made by them was that by combining ECAP with cold rolling a higher hydrogen uptake and faster sorption kinetics were attained, which was associated with a favorable (002) texture produced at the cold-working stage (Crivello et al., 2016). A similar observation was made by Asselli et al. (2015) who showed that ECAP alone (6 passes using a die with a channel angle of $110^{\circ}$ ) was not efficient and that it took extra processing by Accumulated Roll Bonding (ARB), with subsequent pulverization of the billet into small platelets, to achieve reasonably high level of hydrogen uptake and accelerated hydrogenation kinetics of ZK60.

Conditioning by ECAP processing for better hydrogen sorption performance proposed in Skripnyuk et al. (2004) was adopted for a range of other $\mathrm{Mg}$ alloys. While in our first exercise with ZK60 an "off the shelf" alloy was used, our next approach (Skripnyuk et al., 2007) was to use a smart alloy design. The material of choice was a eutectic $\mathrm{Mg}-\mathrm{Ni}$ alloy with the $\mathrm{Mg}_{89} \mathrm{Ni}_{11}$ composition. The motivation behind this choice was two-fold: first, Ni was known for its positive catalytic effect on hydrogen sorption properties of Mg; second, it was hoped that the fine lamellar structure of the eutectic would be conducive for further microstructure refinement by ECAP that would boost the hydrogenation/dehydrogenation kinetics. As a matter of fact, earlier work on cold rolling of $\mathrm{Mg}$ and Ni sheets with subsequent 



FIGURE 3 | Bright field TEM micrographs of the as cast (A,B) and ECAP-modified (C-F) Mgrg Ni ${ }_{11}$ alloy: after a single ECAP pass (C,D) and 10 ECAP passes (E,F). Reproduced from Skripnyuk et al. (2007) with permission from Elsevier.

hydrogenation produced Mg-Ni laminates containing nano scale magnesium hydrides with good electrochemical properties (Ueda et al., 2004; Pedneault et al., 2008). Our alternative ECAPbased approach (Skripnyuk et al., 2007) presumed that the lamellar eutectic structure, with brittle $\mathrm{Mg}_{2} \mathrm{Ni}$ phase encased in ductile lamellae of Mg-based solid solution, would lead to in situ nanostructuring of the $\mathrm{Mg}_{2} \mathrm{Ni}$ phase without disintegration of the alloy during processing. This effort did pay off both in terms of the extreme microstructure refinement (Figure 3) and the hydrogen sorption behavior. Specifically, 10 ECAP passes lifted the equilibrium pressure by about $50 \%$. Most importantly, the desorption kinetics was improved substantially, to a larger extent than by any other known processing method. Thus, at $300^{\circ} \mathrm{C} 5 \%$ of hydrogen were desorbed within $<5 \mathrm{~min}$. It 
is interesting to note that a significantly higher level of size refinement of the $\mathrm{Mg}_{2} \mathrm{Ni}$ phase achieved by rapid solidification of a series of $\mathrm{Mg}$-rich $\mathrm{Mg}-\mathrm{Ni}$ alloys did not lead to any appreciable improvement of hydrogen storage properties (Bendersky et al., 2011). This demonstrates that in addition to the grain and precipitate size refinement, intrinsic defects introduced by severe plastic straining (such as non-equilibrium grain boundaries and dislocations in the $\mathrm{Mg}$ matrix) play an important role in improving the hydrogenation properties.

Other authors investigated the effect of ECAP on the hydrogen sorption properties of such magnesium alloys as AZ31 (Leiva et al., 2009; Chiu et al., 2018; Skryabina et al., 2019), AZ61 (Huang et al., 2018), Mg-Mm-Ni (Mm = mischmetal) (Løken et al., 2007), and Mg-Gd-Y-Zn-Zr (Lapovok et al., 2018) —with various degrees of success. Useful summaries of the results obtained by employing ECAP as a tool for tuning the hydrogen sorption properties of $\mathrm{Mg}$ alloys was recently provided by Wang et al. (2017) and Huot et al. (2012).

\section{Alloys Processed by High Pressure Torsion}

While the high efficacy of equal-channel angular pressing in terms of the ease of material handling and throughput is a great benefit of this method, other SPD techniques are of interest as well. High-pressure torsion (HPT) takes a special place among these techniques, as the degree of grain refinement it provides is exceptionally high, the grain sizes attainable in metallic materials often falling in the $100 \mathrm{~nm}$ range, cf. (Zhilyaev and Langdon, 2008; Estrin and Vinogradov, 2013). Accordingly, several research groups hold high expectations of HPT as a technique for improving hydrogen sorption in $\mathrm{Mg}$ alloys. A recent review of the effect of HPT on hydrogen sorption of Mg alloys was published by Edalati et al. (2018a). This work is part of a concerted effort of Japanese researchers in the area of SPD-enabled hydrogen storage material, which started with a contribution by Kusadome et al. (2007) who successfully applied $\mathrm{HPT}$ to enhance the hydrogenation of a $\mathrm{Mg}_{2} \mathrm{Ni}$ intermetallic. HPT, along with ECAP and cold rolling, was also employed in an attempt to enhance the hydrogen sorption kinetics of ball-milled nanocrystalline $\mathrm{Mg}_{2} \mathrm{Ni}$ powders (Révész et al., 2010). The use of HPT processing for improving the hydrogen storage performance of $\mathrm{Mg}_{2} \mathrm{Ni}$ intermetallic by Hongo et al. (2015) at Kyushu University, Fukuoka, Japan was guided by the idea that deformation-induced stacking faults may play a role similar to that of grain boundaries, thus accelerating the hydrogen sorption. To elucidate the effect of the stacking faults, the authors of Hongo et al. (2015) used two processing routes: casting and HPT (10 anvil revolutions, $N=10$ ). In both cases, subsequent annealing at $673 \mathrm{~K}$ was used to produce a coarse-grained structure. The imprint of HPT was the presence of deformation-induced stacking faults that were retained after annealing. The superior hydrogen sorption kinetics of the material containing the HPTinduced stacking faults is evident in Figure 4.

The Kyushu University group conducted a systematic study of the HPT-driven synthesis of binary and tertiary Mg-based alloys (Edalati et al., 2018a). It was shown that by mechanical mixing of $\mathrm{Mg}$ powders with powders of various elements and further processing these blends by means of HPT, nanograined

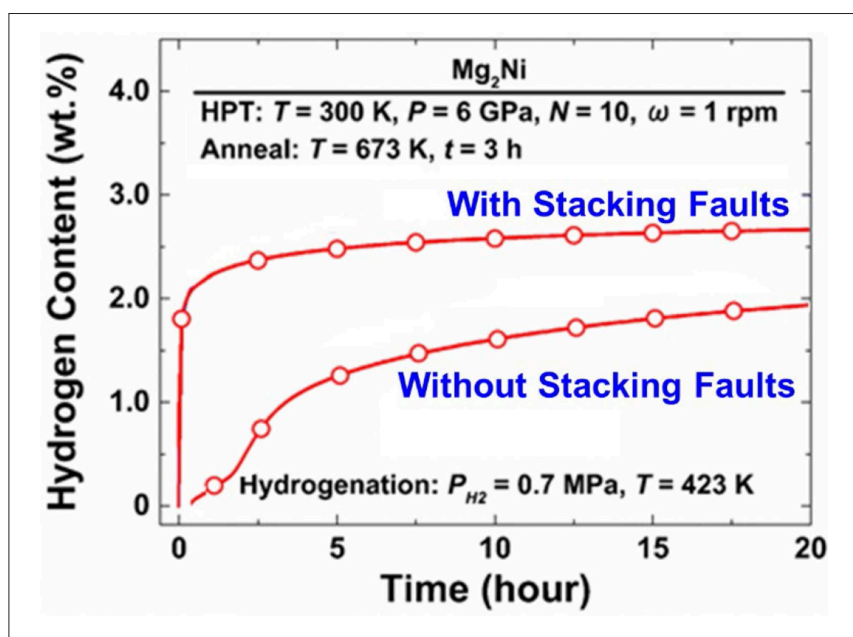

FIGURE 4 | Hydrogenation kinetics of an $\mathrm{Mg}_{2} \mathrm{Ni}$ intermetallic with and without HPT-induced stacking faults. The processing and test conditions are indicated within the diagram. Reproduced from Hongo et al. (2015) with permission from Elsevier.

intermetallics, metastable phases, or amorphous phases can be obtained, depending on the composition (Kusadome et al., 2007). An excellent potential of HPT for producing a broad range of $\mathrm{Mg}$ based alloys and compounds for hydrogen storage applications was thus demonstrated.

A particular result of note is the successful fabrication by HPT of a Mg alloy with good hydrogen sorption properties at room temperature (Edalati et al., 2018b). What is quite remarkable is that the alloy was first designed in silico using first principle calculations and then synthesized by HPT. The compound they designed, $\mathrm{Mg}_{4} \mathrm{NiPd}$, is characterized by a low hydrogen binding energy, which is the reason for its favorable hydrogen storage properties. It was produced by casting and subsequent HPT to a very large number of anvil revolutions $(N=1,500)$ under a pressure of $6 \mathrm{GPa}$, which resulted in a homogeneous distribution of the constituent elements in a body-centered cubic lattice of the $\mathrm{CsCl}$ type (Figure 5). Also shown are the hydrogen pressure vs. hydrogen content diagrams, which demonstrate reasonably good hydrogen sorption properties of the material at room temperature $(305 \mathrm{~K})$.

The last decade saw a marked growth of activities in HPT processing of $\mathrm{Mg}$ and magnesium alloys for hydrogen storage applications, the Kyushu University group and other teams (Leiva et al., 2010; Botta et al., 2013; Panda et al., 2017) being the major drivers of this research. A report on HPT processing of $\mathrm{Mg}$ alloys (including hydrogen sorption results) published recently by Figueiredo and Langdon (2019) complements the review by Edalati et al. (2018a). Together they provide a comprehensive picture of research activities in this field. One can anticipate further developments in two directions: broadening the compositional base of HPT-induced synthesis of Mg-based alloys in a search for those with favorable thermodynamic and kinetic properties and perfecting the processing. A way to transcend the limitations of HPT with regard to the specimen size and the process throughput by employing its semi-continuous 





FIGURE 5 | SEM-EDS elemental mapping of HPT-processed $\mathrm{Mg}_{4}$ NiPd for different numbers of anvil revolutions [frames (a) to (e)] (left) and hydrogen pressure vs. hydrogen content diagrams at room temperature (right). Reproduced from Edalati et al. (2018b) with permission from Elsevier.

version, the so-called High-Pressure Torsion Extrusion (HPTE), was recently proposed in Omranpour et al. (2019). It was demonstrated for the case of $\mathrm{Nb}$ that HPTE gives rise to faster hydrogenation kinetics than ECAP. The efficacy of the process as applied to $\mathrm{Mg}$ based materials is yet to be evaluated.

\section{Mg-Based Composites}

One of the promising strategies to lower the reaction enthalphy of Mg-based hydrides is to combine them with other metal hydrides to composites (Dornheim et al., 2007; Crivello et al., 2016; Yartys et al., 2019). Due to their capability of enabling mixing and compaction of powders, SPD techniques are wellsuited for processing composite materials targeting hydrogen storage applications. As an example, $\mathrm{Mg}$-based nanocomposites were produced by HPT of stacks of disks of different materials (Figueiredo and Langdon, 2019). Another option is to produce Mg-based composites (notably, nanocomposites) with carbonaceous materials (Ruse et al., 2017; Yartys et al., 2019). With the high hydrogen storage capacity of carbon nanotubes and their expected catalytic effect on hydrogen sorption in magnesium in sight (Ruse et al., 2017), we synthesized a Mgbased composite with 2 wt.\% of multiwall carbon nanotubes (MWCNT). The as-sintered composite was processed by one or two ECAP passes. The hydrogen storage properties of the assintered and the ECAP-processed composites were determined by volumetric method and compared with those of pure $\mathrm{Mg}$. The observed effects of the addition of MWCNTs to Mg consisted in an appreciable enhancement of hydrogen desorption rate, the disappearance of the pressure hysteresis, and an increase in the slope of the pressure plateau in the PCIs measured at $573 \mathrm{~K}$.
Compared with pure $\mathrm{Mg}$, the hydrogen desorption pressure for the as-sintered composite was by some $50 \%$ higher. Against our expectations based on earlier observations of the effect of ECAP on the hydrogen sorption/desorption, the hydrogen desorption pressure was lowered by ECAP processing of the assintered composite. Based on transmission electron microscopy observations, it was conjectured that this negative effect owes to ECAP-induced defects in MWCNTs and changes in the morphology of Mg-MWCNT interfaces.

A recently obtained insight into hydrogenation mechanisms of Mg-MWCNT composites processed by HEBM can be useful for understanding some aspects of the effect of SPD on hydrogen storage properties of $\mathrm{Mg}$ alloys (Popilevsky et al., 2017). It was found that prolonged milling transforms the MWCNTs into chains of carbon nanoparticles. The latter serve as preferential sites for the nucleation of hydride phase, resulting in its oblong morphology and a microstructure consisting of interpenetrating networks of metal and hydride phases (Popilevsky et al., 2017). This network allows rapid supply of hydrogen to the metal-hydride interface during the late stages of hydrogenation, since the diffusion coefficient of hydrogen in the $\mathrm{Mg}$ metal phase is several orders of magnitude higher than in the hydride phase. Also, a percolating network of the metal phase retained up to the late stages of the metalhydride transformation ensures high thermal conductivity of the composite, which is essential for rapid removal of heat generated by the exothermic hydrogenation reaction. This example demonstrates that detailed studies of the microstructure of the SPD-processed Mg-based alloys at various stages of hydrogenation may hold a key to understanding the positive 
effects of SPD. For example, the SPD-induced crystal lattice defects may lower the barriers for nucleation of the hydride phase and change its growth morphology.

\section{CONCLUSION}

In summary, while the SPD has only a moderate effect on the thermodynamics of Mg-hydrogen interaction, its influence on the kinetics of hydrogenation is substantial and is comparable with that of HEBM. Also, the SPD-based methods can significantly shorten the time needed for initial activation of the Mg-based alloys, or eliminate it altogether (Botta et al., 2013). This is a very important factor that can significantly reduce the overall cost of a commercial hydrogen storage system. As for the thermodynamics of $\mathrm{Mg}-\mathrm{H}$ interaction, realistic estimates indicate that its significant change by crystal lattice defects, surfaces, interfaces, and internal stresses is unlikely (Berube et al., 2008; Chung et al., 2012). We are of the opinion that the most promising way of improving the thermodynamics of the $\mathrm{Mg}-\mathrm{H}$ system is to combine the SPD techniques with multicomponent alloying, preferably with light elements. The effect of alloying on the thermodynamics of the Mg-H system is well established (Chung et al., 2012; Skripnyuk and Rabkin, 2012), and employing the computational thermodynamics methods (such as CALPHAD) may be helpful in identifying the most promising alloying elements and alloy compositions. While the detailed mechanisms underlying the improved kinetics of hydrogen absorption and desorption of SPD-processed Mg alloys still need to be unraveled, it is undoubtable that they are associated with a high concentration of crystal lattice defects (or even partial or full amorphisation of the material), cf. (Skripnyuk et al., 2004; Edalati et al., 2018a). Dislocations and grain boundaries generated as a result of severe plastic deformation provide fast diffusion pathways for hydrogen and alloying elements that may have a catalytic effect on the hydrogen sorption properties. The role of these defects in facilitating the nucleation of the hydride phase and in optimizing its growth morphology is to be considered as well. It should also be mentioned that SPD processing may generate channels for ultra-fast diffusion, which is more rapid than what could be expected from an increased

\section{REFERENCES}

Asselli, A. C., Leiva, D. R., Huot, J., Kawasaki, M., Langdon, T. G., and Botta, W. J. (2015). Effects of equal-channel angular pressing and accumulative roll-bonding on hydrogen storage properties of a commercial ZK60 magnesium alloy. Int. J. Hydrogen Energy 40, 16971-16976. doi: 10.1016/j.ijhydene.2015.05.149

Bendersky, L. A., Chiu, C., Skripnyuk, V. M., and Rabkin, E. (2011). Effect of rapid solidification on hydrogen solubility in Mg-rich $\mathrm{Mg}-\mathrm{Ni}$ alloys. Int. J. Hydrogen Energy 36, 5388-5399. doi: 10.1016/j.ijhydene.2011. 01.133

Berube, V., Chen, G., and Dresselhaus, M. S. (2008). Impact of nanostructuring on the enthalpy of formation of metal hydrides. Int. J. Hydrogen Energy 33, 4122-4131. doi: 10.1016/j.ijhydene.2008.05.083

Birnbaum, H. (2005). Fueling the 'freedom car'. Mater. Today 8, 64-64. doi: 10.1016/S1369-7021(05)00718-2 area of a grain boundary network in a grain-refined material (Divinski et al., 2010, 2011). Texture effects may also be at play (Crivello et al., 2016).

We believe that SPD processing of $\mathrm{Mg}$ based alloys has a great potential as a pathway to producing efficient hydrogen storage materials. Even if we are still far away from developing such materials for automotive applications, the available data show that the groundwork made so far promises breakthroughs in the realm of stationary hydrogen and heat storage facilities. The benefits of using SPD techniques over ball milling include much lower health hazards, greater amounts of material produced, relative ease of implementation at industry scale, and much higher energy efficiency (Yartys et al., 2019). Some concerns about the limited applicability of the mentioned SPD processing techniques relating to the discontinuous nature of ECAP or small quantities of material produced by HPT (Estrin and Vinogradov, 2013) could be allayed owing to some developments of SPD technology. Specifically, integration of ECAP with other processing techniques, such as Conform (Raab et al., 2004) or direct extrusion (Orlov et al., 2011), turns the process in a semicontinuous one. Similarly, a modification of the conventional HPT technique combining it with extrusion (Ivanisenko et al., 2016) makes it possible to produce long billets with ultrafinegrained structure. These upscaled SPD methods can be employed to fabricate ultrafine-grained $\mathrm{Mg}$ alloys targeting hydrogen storage applications. Thus, what began as a first exercise in improving hydrogen sorption properties of a $\mathrm{Mg}$ alloy by SPD (Skripnyuk et al., 2004) has developed to a thriving area of research with a great promise for viable industrial applications.

\section{AUTHOR CONTRIBUTIONS}

ER, VS, and YE have contributed to the development of the concept and the writing of this manuscript equally.

\section{ACKNOWLEDGMENTS}

ER and VS wish to thank the Israeli Ministry of National Infrastructures, Energy and Water Resources for partial support of this work (Project 216-11-023).

Botta, W. J., Jorge, A. M., Veron, M., Rauch, E. F., Ferrie, E., Yavari, A. R., et al. (2013). H-sorption properties and structural evolution of $\mathrm{Mg}$ processed by severe plastic deformation. J. Alloy. Compd. 580, S187-S191. doi: 10.1016/j.jallcom.2013.03.013

Chiu, C., Huang, S.-J., Chou, T.-Y., and Rabkin, E. (2018). Improving hydrogen storage performance of AZ31 Mg alloy by equal channel angular pressing and additives. J. Alloys Compd. 743, 437-447. doi: 10.1016/j.jallcom.2018.01.412

Chung, C. J., Lee, S. C., Groves, J. R., Brower, E. N., Sinclair, R., and Clemens, B. M. (2012). Interfacial alloy hydride destabilization in $\mathrm{Mg} / \mathrm{Pd}$ thin films. Phys. Rev. Lett. 108:106102. doi: 10.1103/PhysRevLett.108.106102

Crivello, J. C., Dam, B., Denys, R. V., Dornheim, M., Grant, D. M., Huot, J., et al. (2016). Review of magnesium hydride-based materials: development and optimisation. Appl. Phys. A 122:97. doi: 10.1007/s00339-016-9602-0

Divinski, S., Wilde, G., Rabkin, E., and Estrin, Y. (2010). Ultra-fast atomic transport in severely deformed materials-A pathway to applications? Adv. Eng. Mater. 12, 779-785. doi: 10.1002/adem.200900340 
Divinski, S. V., Reglitz, G., Roessner, H., Estrin, Y., and Wilde, G. (2011). Ultrafast diffusion channels in pure Ni severely deformed by equal-channel angular pressing. Acta Mater. 59, 1974-1985. doi: 10.1016/j.actamat.2010.11.063

Dornheim, M., Doppiu, S., Barkhordarian, G., Boesenberg, U., Klassen, T., Gutfleisch, O., et al. (2007). Hydrogen storage in magnesiumbased hydrides and hydride composites. Scripta Mater. 56, 841-846. doi: 10.1016/j.scriptamat.2007.01.003

Edalati, K., Akiba, E., and Horita, Z. (2018a). High-pressure torsion for new hydrogen storage materials. Sci. Techn. Adv. Mater. 19, 185-193. doi: $10.1080 / 14686996.2018 .1435131$

Edalati, K., Uehiro, R., Ikeda, Y., Li, H.-W., Emami, H., Filinchuk, Y., et al. (2018b). Design and synthesis of a magnesium alloy for room temperature hydrogen storage. Acta Mater. 149, 88-96. doi: 10.1016/j.actamat.2018.02.033

Estrin, Y., and Vinogradov, A. (2013). Extreme grain refinement by severe plastic deformation: a wealth of challenging science. Acta Mater. 61, 782-817. doi: 10.1016/j.actamat.2012.10.038

Figueiredo, R., and Langdon, T. G. (2019). Processing magnesium and its alloys by high-pressure torsion: an overview. Adv. Eng. Mater. 21:1801039. doi: 10.1002/adem.201801039

Graetz, J. (2012). Metastable metal hydrides for hydrogen storage. ISRN Mater. Sci. 2012:863025. doi: 10.5402/2012/863025

Hardian, R., Pistidda, C., Chaudhary, A. L., Capurso, G., Gizer, G., Cao, H., et al. (2018). Waste Mg-Al based alloys for hydrogen storage. Int. J. Hydrogen Energy 43, 16738-16748. doi: 10.1016/j.ijhydene.2017.12.014

Hongo, T., Edalati, K., and Arita, M. (2015). Significance of grain boundaries and stacking faults on hydrogen storage properties of $\mathrm{Mg}_{2} \mathrm{Ni}$ intermetallics processed by high pressure torsion. Acta Mater. 92, 46-54. doi: 10.1016/j.actamat.2015.03.036

Huang, S.-J., Chiu, C., Chou, T.-Y., and Rabkin, E. (2018). Effect of equal channel angular pressing (ECAP) on hydrogen storage properties of commercial magnesium alloy AZ61. Int. J. Hydrogen Energy 43, 4371-4380. doi: 10.1016/j.ijhydene.2018.01.044

Huot, J. (2010). "Metal hydrides," in Handbook of Hydrogen Storage, ed M. Hirscher (Weinheim: Wiley-VCH Verlag GmbH \& Co. KgaA), 81-116. doi: 10.1002/9783527629800.ch4

Huot, J., Skryabina, N., and Fruchart, D. (2012). Application of severe plastic deformation techniques to magnesium for enhanced hydrogen sorption properties. Metals 2, 329-343. doi: 10.3390/met2030329

Ivanisenko, Y., Kulagin, R., Fedorov, V., Mazilkin, A., Scherer, T., Baretzky, B., et al. (2016). High pressure torsion extrusion as a new severe plastic deformation process. Mater. Sci. Eng. A 64, 247-256. doi: 10.1016/j.msea.2016.04.008

Jena, P. (2011). Materials for hydrogen storage: past, present, and future. J. Phys. Chem. Lett. 2, 206-2011. doi: 10.1021/jz1015372

Krystian, M., Zehetbauer, M. J., Kropik, H., Mingler, B., and Krexner, G. (2011). Hydrogen storage properties of bulk nanostructured ZK60 Mg alloy processed by equal channel angular pressing. J. Alloys Compd. 509, 449-455. doi: 10.1016/j.jallcom.2011.01.029

Kusadome, Y., Ikeda, K., Nakamori, Y., and Orimo, S., Horita, z. (2007). Hydrogen storage capability of $\mathrm{MgNi}_{2}$ processed by high pressure torsion. Scripta Mater. 57, 751-753. doi: 10.1016/j.scriptamat.2007.06.042

Lapovok, R., Zolotoyabko, E., Berner, A., Skripnyuk, V., Lakin, E., Larianovsky, N., et al. (2018). Hydrogenation effect on microstructure and mechanical properties of Mg-Gd-Y-Zn-Zr alloys. Mater. Sci. Eng. A 719, 171-177. doi: 10.1016/j.msea.2018.02.016

Leiva, D. R., Fruchart, D., Bacia, M., Girard, G., Skryabina, N., A., et al. (2009). Mg alloys for hydrogen storage processed by SPD. Int. J. Mat. Res. 100, 1739-1746. doi: $10.3139 / 146.110225$

Leiva, D. R., Jorge, A. M., Ishikawa, T. T., Huot, J., Fruchart, D., Miraglia, S., et al. (2010). Nanoscale grain refinement and H-sorption properties of $\mathrm{MgH}_{2}$ processed by high-pressure torsion and other mechanical routes. Adv. Eng. Mater. 12, 786-792. doi: 10.1002/adem.201000030

Løken, S., Solberg, J. K., Maehlen, J. P., Denys, R. V., Lototsky, M. V., Tarasov, B. P., et al. (2007). Nanostructured $\mathrm{Mg}-\mathrm{Mm}-\mathrm{Ni}$ hydrogen storage alloy: structure-properties relationship. J. Alloy. Compd. 446-447, 114-120. doi: 10.1016/j.jallcom.2006.11.200

Luo, Q., Li, J., Li, B., Liu, B., Shao, H., and Li, Q. (2019). Kinetics in Mg-based hydrogen storage materials: enhancement and mechanism. Magnesium J. Alloys 7, 58-71. doi: 10.1016/j.jma.2018.12.001
Omranpour, B., Kommel, L., Sanchez, E. G., Ivanisenko, J., and Huot, J. (2019). Enhancement of hydrogen storage in Metals by using a new technique in Severe Plastic Deformations. Key Eng. Mater. 799, 173-178. doi: 10.4028/www.scientific.net/KEM.799.173

Orlov, D., Raab, G., Lamark, T. T., Popov, M., and Estrin, Y. (2011). Improvement of mechanical properties of magnesium alloy ZK60 by integrated extrusion and equal channel angular pressing. Acta Mater. 59, 375-385. doi: 10.1016/j.actamat.2010.09.043

Panda, S., Fundenberger, J.-J., Zhao, Y., Zou, J., Toth, L. S., and Grosdidier, T. (2017). Effect of initial powder type on the hydrogen storage properties of highpressure torsion consolidated Mg. Int. J. Hydrogen Energy 42, 22438-22448. doi: 10.1016/j.ijhydene.2017.05.097

Pedneault, S., Huot, J., and Roué, L. (2008). Nanostructured $\mathrm{Mg}_{2} \mathrm{Ni}$ materials prepared by cold rolling and used as negative electrode for Ni-MH batteries. J. Power Source 185, 566-569. doi: 10.1016/j.jpowsour.2008. 06.077

Popilevsky, L., Skripnyuk, V. M., Amouyal, Y., and Rabkin, E. (2017). Tuning the thermal conductivity of hydrogenated porous magnesium hydride composites with the aid of carbonaceous additives. Int. J. Hydrogen Energy 42, 22395-22405. doi: 10.1016/j.ijhydene.2017.04.088

Raab, G. I., Valiev, R. Z., Lowe, T. C., Zhu, Y. T., Raab, G. J., Valiev, R. Z., et al. (2004). Continuous processing of ultrafine grained $\mathrm{Al}$ by ECAP-Conform. Mater. Sci. Eng. A 382 30-34. doi: 10.1016/j.msea.2004. 04.021

Révész, Á., Kánya, Z., Verebélyi, T., Szabó, P. J., Zhilyaev, A. P., and Spassov, T. (2010). The effect of high-pressure torsion on the microstructure and hydrogen absorption kinetics of ball-milled Mg70Ni30. J Alloys Compd. 504, 83-88. doi: 10.1016/j.jallcom.2010.05.058

Ruse, E., Buzaglo, M., Pevsner, S., Pri Bar, I., Skripnyuk, V. M., Rabkin, E., et al. (2017). Tuning Mg hydriding kinetics with nanocarbons. J. Alloys Compd. 725, 616-622. doi: 10.1016/j.jallcom.2017.07.166

Schlapbach, L., and Züttel, A. (2001). Hydrogen-storage materials for mobile applications. Nature 414, 353-358. doi: 10.1038/35104634

Schneemann, A., White, J. L., Kang, S., Jeong, S., Wan, L. F., Cho, E. S., et al. (2018). Nanostructured metal hydrides for hydrogen storage. Chem. Rev. 118, 10775-10839. doi: 10.1021/acs.chemrev.8b00313

Shao, H., He, L., Lin, H., and Li, H.-W. (2018). Progress and trends in magnesiumbased materials for energy-storage research: a review. Energy Technol. 6, 445-458. doi: 10.1002/ente.201700401

Skripnyuk, V., Buchman, E., Rabkin, E., Estrin, Y., Popov, M., and Jorgensen, S. (2007). The effect of equal channel angular pressing on hydrogen storage properties of a Mg-Ni alloy. J. Alloy. Compd. 436, 99-106. doi: 10.1016/j.jallcom.2006.07.030

Skripnyuk, V. M., and Rabkin, E. (2012). $\mathrm{Mg}_{3} \mathrm{Cd}$ : a model alloy for studying the destabilization of magnesium hydride. Int. J. Hydrogen Energy 37, 10724-10732. doi: 10.1016/j.ijhydene.2012.04.065

Skripnyuk, V. M., Rabkin, E., Estrin, Y., and Lapovok, R. (2004). The effect of ball milling and equal channel angular pressing on the hydrogen absorption/desorption properties of $\mathrm{Mg}-4.95 \mathrm{wt} \% \mathrm{Zn}-0.71 \mathrm{wt} \% \mathrm{Zr}$ (ZK60) alloy. Acta Mater. 52, 405-414. doi: 10.1016/j.actamat.2003. 09.025

Skripnyuk, V. M., Rabkin, E., Estrin, Y., and Lapovok, R. (2009). Improving hydrogen storage properties of magnesium based alloys by equal channel angular pressing.Int. J. Hydrogen Energy 35, 6320-6324. doi: 10.1016/j.ijhydene.2009.05.136

Skryabina, N., Aptukov, V., Romanov, P., Fruchart, D., de Rango, P., Girard, G., et al. (2019). Microstructure optimization of Mg-alloys by the ECAP process including numerical simulation, SPD treatments, characterization, and hydrogen sorption properties. Molecules 24, 89-120. doi: 10.3390/molecules 24010089

Soyama, J., Floriano, R., Leiva, D. R., and Guo, Y. (2016). Severely deformed ZK60 $+2.5 \% \mathrm{Mm}$ alloy for hydrogen storage produced by two different processing routes. Int. J. Hydrogen Energy 41, 11284-11292. doi: 10.1016/j.ijhydene.2016.05.031

Ueda, T. T., Tsukahara, M., Kamiya, Y., and Kikuchi, S. (2004). Preparation and hydrogen storage properties of $\mathrm{Mg}-\mathrm{Ni}-\mathrm{Mg}_{2} \mathrm{Ni}$ laminate composites. J. Alloy. Compd. 386, 253-257. doi: 10.1016/j.jallcom.2004. 04.154 
Valiev, R. Z., Estrin, Y., Horita, Z., Langdon, T. G., Zehetbauer, M. J., and Zhu, Y. (2016). Producing bulk ultrafine-grained materials by severe plastic deformation: ten years later. JOM 68:121626. doi: 10.1007/s11837-0161820-6

Valiev, R. Z., Islamgaliev, R. K., and Alexandrov, I. V. (1999). Bulk nanostructured materials from severe plastic deformation. Progr. Mater. Sci. 12:18.

Walker, G. (2011). Solid-State Hydrogen Storage: Materials and Chemistry. Cambridge: Woodhead Publishing Ltd.

Wang, J.-Y., Wu, C.-Y., Nieh, J.-K., Lin, H.-C., Lin, K. M., and Bor, H.-Y. (2010). Improving the hydrogen absorption properties of commercial $\mathrm{Mg}-\mathrm{Zn}-\mathrm{Zr}$ alloy. Int. J. Hydrogen Energy 35, 1250-1256. doi: 10.1016/j.ijhydene.2009.11.005

Wang, L., Jiang, J., Ma, A., Li, Y., and Song, D. (2017). A critical review of Mg-based hydrogen storage materials processed by equal channel. Ang. Press. Metals 27:324. doi: 10.3390/met7090324

Yartys, V. A., Lototskyy, M. V., Akiba, E., Albert, R., Antonov, V. E., Ares, J. R., et al. (2019). Magnesium based materials for hydrogen based energy storage: past, present and future. Intl. J. Hydrogen Energy 15, 7809-7859. doi: 10.1016/j.ijhydene.2018.12.212
Zhang, J., Li, Z., Wu, Y., Guo, X., Ye, J., Yuan, B., et al. (2019). Recent advances on the thermal destabilization of $\mathrm{Mg}$-based hydrogen storage materials. RSC Adv. 9, 408-428. doi: 10.1039/C8RA05596C

Zhilyaev, A. P., and Langdon, T. G. (2008). Using high-pressure torsion for metal processing: fundamentals and applications. Progr. Mater. Sci. 53, 893-1024. doi: $10.1016 /$ j.pmatsci.2008.03.002

Conflict of Interest: The authors declare that the research was conducted in the absence of any commercial or financial relationships that could be construed as a potential conflict of interest.

Copyright (c) 2019 Rabkin, Skripnyuk and Estrin. This is an open-access article distributed under the terms of the Creative Commons Attribution License (CC BY). The use, distribution or reproduction in other forums is permitted, provided the original author(s) and the copyright owner(s) are credited and that the original publication in this journal is cited, in accordance with accepted academic practice. No use, distribution or reproduction is permitted which does not comply with these terms. 